\title{
Japanese Encephalitis Vaccination in Children Population of Nepal During the year 2005, 2006 and 2008
}

\author{
Joshi DD ${ }^{1}$ \\ ${ }^{1}$ Dr. Durga Datt Joshi, MPVM, FISCD, WHO Expert Panel Member on Zoonoses, Executive Chairman, National \\ Zoonoses and Food Hygiene Research Centre (NZFHRC) GPO Box: 1885 Chagal, Kathmandu, Nepal. Jeevan Smriti \\ Marg House no. 468 Ward no. 13, KMC Phone: +977-1-4270667, +977-1-4272694
}

Address for Correspondence: Dr. Durga Datt Joshi, E-mail: ddjoshi@healthnet.org.np

\begin{abstract}
Japanese Encephalitis (JE) is caused by a Flavivirus that, in a proportion of human cases, causes severe encephalitis leading to death or sometimes permanent disablement. It is a zoonotic disease, transferred from animals (commonly pigs or wild birds) by a mosquito vector to humans. In Southeast Asia it is thought to cause up to 50000 clinical cases and 10000 deaths per year. JE vaccination programme was carried out in high risk districts of Nepal. Japanese encephalitis vaccination was carried out during the years 2005, 2006, 2008 and 2009. The data collected from primary and secondary sources from the District Health Offices and other concerned central offices of the Department of Health Services, was tabulated and analysed. Thirty-five lakh of JE vaccine doses was procured by the Ministry of Health during the year 2006/2007. This vaccine was used in children under 15 years of age of 12 districts of JE risk and high-risk areas of Nepal. It was found that during the year 2005; 85\% children in Banke and 81\% in Kailali were vaccinated against JE. In Kailali and Banke districts it was found to be about $103 \%$ coverage in children population targeted, in Dang district it was 100\% coverage, and in Bardiya district it was $73 \%$ coverege but in Rupandehi and Kanchanpur districts it was only about $40 \%$ and $41 \%$ respectively. JE vaccine coverage was very low in two Rupandehi and Kanchanpur districts during 2005 and 2006 and very high coverage during the year 2008. JE vaccination coverage results for the year 2009 have not been made available yet due to unavailability of data. This type of mass vaccination campaign needs regularlity, mass awareness and health education programme should be carried out before JE vaccination campaign in the children in the future.
\end{abstract}

Key words: Japanese Encephalitis, flavivirus, zoonotic, vector borne, lyophilized vaccine.

\section{What is the situation?}

Tepal is one of the richest countries in the world in 1 terms of bio-diversity due to its unique geographical position and altitudinal variation. The elevation of the country ranges from $60 \mathrm{~m}$ above sea level to the highest point on earth, Mr. Everest at $8,848 \mathrm{~m}$, all within a distance of $150 \mathrm{~km}$ resulting into climatic conditions from Sub-tropical to Artic mentioned by Nepal Tourism Board, 2006. JE cases are observed mostly in Terai area $^{1}$. In Southeast Asia it is thought to cause up to 50000 clinical cases and 10000 deaths per year ${ }^{2}$. The earlier reports have shown that the case fatality rate
(CFR) is high in Nepal, and nationwide it has ranged from $15 \%$ to $46 \%$ for the years 1978 to 1994 .

Japanese Encephalitis (JE) has been occurring in the South-East Asia and Western Pacific Regions for a long time. In Nepal, it has occurred first time in Rupandehi district then in Sunsari, Morang and latter in all 23 districts of tarai and inner tarai ${ }^{1}$. Incidence of this disease has been recorded first time in different years in the following countries. Japan, China and Republic of Korea have reduced the incidence of this disease now ${ }^{2}$. 
Table 1: Historical Reviews of JE Outbreak Worldwide.

\begin{tabular}{|l|l|}
\hline Japan & 1949 to 1950 \\
\hline Egypt & 1977 \\
\hline Republic of Korea. & 1949 to 1958 \\
\hline China & 1949 \\
\hline Malaysia & 1955 to 1960 \\
\hline Indonesia & 1955 to 1960 \\
\hline Philippines & 1950 to 1955 \\
\hline Singapore & 1955 to 1960 \\
\hline Bangladesh & 1977 \\
\hline Vietnam & 1958 to 1969 \\
\hline India & 1955 (South), 1973 \\
\hline Burma & 1974 \\
\hline $\begin{array}{l}\text { (West Bengal), U.P. and } \\
\text { Bihar }\end{array}$ & 1978 \\
\hline Thailand & 1969 to 1970 \\
\hline Sri Lanka & 1968 \\
\hline Nepal & 1978 \\
\hline
\end{tabular}

The entomological survey conducted, in the month of May/June 1981, in the endemic areas of western region of Nepal, have recorded the prevalence of the following species such as (a) Culex tritaeniorhynchus, (b) Cules Vishuni, (c) Cules Gelidus, (d) Culex fusecephalus, (e) Culex epidesmas (f) Culex bitaeniorhynchus (g) Mansonia annulefera (h) Mansonia indiana (i) Mansonia uniformis, (j) few species of genus Aedes, genus Armigeris and genus Anopheles ${ }^{3}$.

These mosquitos can breed in sub-urban and periurban area provided the ecological condition similar to rural area are present $t^{3,4,5}$.

Infected Population and Deaths from Japanese Encephalitis (JE) Disease in Nepal (EDCD/DHS)

\begin{tabular}{|l|l|}
\hline High Risk Population & 1 Core 25 Lakh \\
\hline High Risk Population & (Below 15 Years) 55 Lakh \\
\hline JE Cases & $\begin{array}{l}\text { 26658 people during the } \\
\text { year 1978-2003 }\end{array}$ \\
\hline Death Cases & $\begin{array}{l}5370 \text { people during the } \\
\text { year 1978-2003 }\end{array}$ \\
\hline Mortality & 5 to 25\% \\
\hline Incidence & $50 \%$ (Below 15 Years) \\
\hline
\end{tabular}

In Nepal JE has been recorded and reported as a seasonal disease in Nepal. "Shrawan" (July and August) appears to have been the deadliest month for the Nepalese as far as human casualties from JE are concerned.
During the summer of 1983,1152 people were immunized against Japanese Encephalitis at British Medical Hospital (BMH), Ghopa camp, Dharan Nepal ${ }^{4}$. This was the first use of the Biken killed lyophilized vaccine in the British Army. Three doses of $1 \mathrm{ml}$. (0.5 $\mathrm{ml}$ for children under 3 years) given 10 days apart produced a protective neutralizing antibody response (titre more than 1:10) in almost $90 \%$ of people. Two doses of vaccine however seemed inadequate in that less than $40 \%$ of people sero-converted. Side effects were minimal and trivial. Studies of neutralizing antibodies before vaccination showed up to $30 \%$ of Nepalese people tested were already immune due to previous in apparent infection while all but one of the British Nationals' were fully susceptible.

\section{What was done?}

Epidemiology and Disease Control Division (EDCD) of the Department of Health Services, Ministry of Health and Population targeted to vaccinate 2,536,000 people of six Terai districts. The EDCD was prepared to vaccinate children between one and 15 years in age in Rupandehi and Kanchanpur districts and the whole population of Dang, Banke, Bardiya and Kailali districts during the year 2005 and 2006. During the year 2007 JE vaccination was not carried out in Nepal. Because of transferring process of this activity from DEE to Child Health Division (CHD).

EDCD launched an immunization campaign in June 2006 in six districts of Terai, which were most affected from Japanese encephalitis. Earlier one-dose vaccines were successfully given as a pilot project in two high risk districts Kailali and Rupandehi in 2005.

Kailali district is the most affected by the disease where vaccination campaign was started from July 2005 onwards according to the Districts Public Health Office. Seven lakh twenty five thousand three hundred ninety nine people have been targeted for vaccination programme for which 1229 vaccination centers were set up in Terai region for which 276 vaccination workers and 3700 volunteers were mobilized. It was conducted in; Kailali, Kanchanpur, Banke, Bardiya and Dang districts which were found to be most affected by encephalitis disease.

From the year 2008 onward Child Health Division, Immunization Unit of the Department of Health Services took the initiation of JE vaccination under routine immunization programme of the children. JE vaccination was done from the month of August to October 2008 in 12 districts of the country. From the month of January to March 2009 JE vaccination was given to the targeted children population of Udayapur, Bara and Rauthat districts. 


\section{What was found?}

JE risk six districts population of children between 1 to 15 age, sex and sex ration in Nepal is presented in Table 2. Japanese Encephalitis (JE) Vaccination in Nepal during the year 2005 is presented in Table 3 and Fig 1. Banke and Kailali district population $(745,099)$ are in high risk group for JE outbreaks. During the year 2005, 85\% children in Banke and $81 \%$ in Kailali were vaccinated against JE. The second highest risk districts Kanchanpur, Bardiya, Dang and Rupandehi children population have got also JE vaccination during the year 2006 as shown in Table 4 and Fig 2. About $103 \%$ vaccination coverage in children population targeted were in Kailali and Banke districts and 100\% coverage in Dang district, $73 \%$ in Bardiya district but in Rupandehi and Kanchanpur district 40 and $41 \% \mathrm{JE}$ vaccine coverage respectively, which was very low coverage.
Total 310,200 children in Rupandehi, 180,500 in Kanchanpur, 534,000 in Dang 445,000 in Banke, 323,000 in Bardiya and 744,000 persons in Kailali districts had been administered the vaccine (See Table 3 and Fig 2).

About 1.5 millionpeople benefited from the Japanese Encephalitis (JE) vaccine in six different districts of the Terai region. These districts are Kanchanpur, Kailali, Banke, Bardiya, Dang and Rupandehi.

The JE vaccinated achievement results of children population from Udayapur, Bara and Rauthat districts have not been made available yet for the year 2009. On an average JE vaccination coverage was $96 \%$ during the year 2008 with the number of targeted children population. However over $100 \%$ coverage is seen in 4 districts out of 9 districts (See Table 5 and Fig 3).

Table 2: JE Risk Six Districts Population of Children between 1 to 15 age, Sex and Sex ration in Nepal

\begin{tabular}{|c|c|c|c|c|c|}
\hline Area & Age group & Total & Male & Female & Sex Ratio \\
\hline \multirow{4}{*}{ Rupendehi } & $0-4$ yrs & 85964 & 43957 & 42007 & 1.05 \\
\hline & $5-9$ yrs & 100724 & 51855 & 48869 & 1.06 \\
\hline & $10-14$ yrs & 93215 & 48354 & 44861 & 1.08 \\
\hline & Total & 279903 & 144166 & 135737 & \\
\hline \multirow{4}{*}{ Dang } & $0-4$ yrs & 59987 & 30284 & 29703 & 0.098 \\
\hline & $5-9$ yrs & 67656 & 34279 & 33377 & 1.02 \\
\hline & $10-14$ yrs & 65860 & 33411 & 32449 & 1.05 \\
\hline & Total & 193503 & 97974 & 95529 & \\
\hline \multirow{4}{*}{ Banke } & $0-4$ yrs & 48809 & 24612 & 24197 & 1.06 \\
\hline & $5-9$ yrs & 56410 & 28955 & 27455 & 1.02 \\
\hline & $10-14$ yrs & 51041 & 26698 & 24343 & 1.03 \\
\hline & Total & 156260 & 80265 & 75995 & \\
\hline \multirow{4}{*}{ Bardiya } & $0-4$ yrs & 47789 & 24246 & 23543 & 1.03 \\
\hline & $5-9$ yrs & 58875 & 29670 & 29205 & 1.02 \\
\hline & $10-14$ yrs & 52823 & 27215 & 25608 & 1.06 \\
\hline & Total & 159487 & 81131 & 78356 & \\
\hline \multirow{4}{*}{ Kailali } & $0-4$ yrs & 79693 & 40843 & 38850 & 1.05 \\
\hline & $5-9$ yrs & 95326 & 48698 & 46628 & 1.04 \\
\hline & $10-14$ yrs & 86588 & 44590 & 41998 & 1.06 \\
\hline & Total & 26160 & 134131 & 127476 & \\
\hline \multirow{4}{*}{ Kanchanpur } & $0-4$ yrs & 49777 & 25506 & 24271 & .099 \\
\hline & $5-9$ yrs & 55802 & 28545 & 27257 & 0.096 \\
\hline & $10-14$ yrs & 52438 & 26790 & 25648 & $0.097 \mathrm{~s}$ \\
\hline & Total & 158017 & 80841 & 77176 & \\
\hline
\end{tabular}

Source: CBS 2001 population census.

Table 3: Japanese Encephalitis (JE) Vaccination in High Risk Targeted Children Population of Banke and Kailali District of Nepal during the Year 2005.

\begin{tabular}{|l|l|c|c|c|}
\hline \multirow{2}{*}{ S. N. } & \multirow{2}{*}{ High Risks district } & \multirow{2}{*}{ Total targeted Children Population } & \multicolumn{2}{|c|}{ Total Vaccination } \\
\cline { 4 - 5 } & & 20,000 & Number & Percentage \\
\hline 1. & Banke & 7,25099 & 17000 & 85.0 \\
\hline 2. & Kailali & $\mathbf{7 4 5 0 9 9}$ & 592147 & 81.7 \\
\hline \multicolumn{2}{r}{ Total } & $\mathbf{6 0 9 1 4 7}$ & $\mathbf{8 1 . 8}$ \\
\hline
\end{tabular}


Table 4: JE Vaccination in Nepal in Children of between one and 15 years in age during the Year 2006.

\begin{tabular}{|l|l|c|c|c|}
\hline \multirow{2}{*}{ S.N. } & \multirow{2}{*}{ District } & \multirow{2}{*}{ Total children population targeted } & \multicolumn{2}{|c|}{ Total Vaccination } \\
\cline { 4 - 5 } & & & Number & Percentage \\
\hline 1. & Rupandehi & 768979 & 310200 & 40 \\
\hline 2. & Dang & 531613 & 534000 & 100 \\
\hline 3. & Banke & 429294 & 445000 & 103 \\
\hline 4. & Bardiya & 438159 & 323000 & 73 \\
\hline 5. & Kailali & 717067 & 744000 & 103 \\
\hline 6. & Kanchanpur & 434117 & 180500 & 41 \\
\hline Total & & $\mathbf{3 3 1 9 2 2 9}$ & $\mathbf{2 5 3 6 7 0 0}$ & $\mathbf{7 6}$ \\
\hline
\end{tabular}

Table 5: JE Vaccination Campaign Coverage Report in 12 Districts of Nepal during the Year 2008.

\begin{tabular}{|c|c|c|c|c|c|c|c|}
\hline \multirow[t]{2}{*}{ S. N. } & \multirow[t]{2}{*}{$\begin{array}{l}\text { Name of } \\
\text { Districts }\end{array}$} & \multirow[t]{2}{*}{ \# VDCs } & \multirow[t]{2}{*}{$\begin{array}{l}\text { \# Municipali- } \\
\text { ties }\end{array}$} & \multirow[t]{2}{*}{$\begin{array}{c}\text { \# Wards in Mu- } \\
\text { nicipalities }\end{array}$} & \multicolumn{2}{|c|}{$\begin{array}{c}\text { Number of Immunized Popu- } \\
\text { lation }\end{array}$} & \multirow[t]{2}{*}{$\begin{array}{c}\text { Coverage } \\
\text { in } \%\end{array}$} \\
\hline & & & & & $\begin{array}{c}\text { Target Popu- } \\
\text { lation (1-15 } \\
\text { years) }\end{array}$ & $\begin{array}{l}\text { Achievement } \\
\text { (1-15 years) }\end{array}$ & \\
\hline 1 & Saptari & 114 & 1 & 10 & 272506 & 246704 & 91 \\
\hline 2 & Udayapur & 44 & 1 & 17 & 140652 & NA & - \\
\hline 3 & Bara & 98 & 1 & 14 & 270174 & NA & - \\
\hline 4 & Rautahat & 96 & 1 & 13 & 261105 & NA & - \\
\hline 5 & Mahottari & 76 & 1 & 13 & 243543 & 247538 & 102 \\
\hline 6 & Jhapa & 47 & 3 & 47 & 304503 & 289043 & 95 \\
\hline 7 & Kapilvastu & 77 & 1 & 14 & 214782 & 199460 & 93 \\
\hline 8 & Nawalparasi & 73 & 1 & 13 & 251005 & 224253 & 89 \\
\hline 9 & Parsa & 82 & 1 & 19 & 219493 & 212399 & 97 \\
\hline 10 & Chitwan & 36 & 2 & 27 & 209400 & 212300 & 101 \\
\hline 11 & Lalitpur & 41 & 1 & 22 & 151244 & 157012 & 104 \\
\hline 12 & Bhaktapur & 16 & 2 & 34 & 100575 & 104094 & 103 \\
\hline \multicolumn{2}{|r|}{ Total } & 800 & 16 & 243 & 1967051 & 1892803 & 96 \\
\hline
\end{tabular}

NA: JE vaccination report has not been made available by districts.

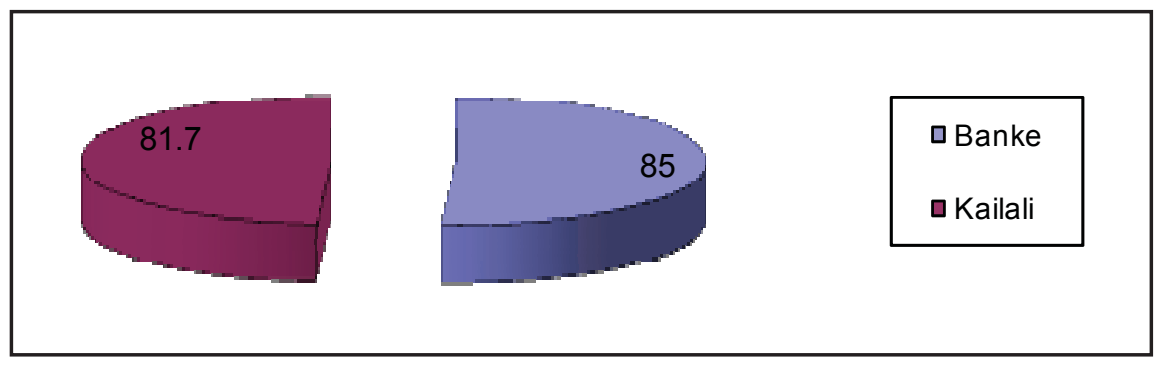

Fig 1: JE Vaccinated Children in Two High risk Districts Banke and Kailali during the Year 2005. 


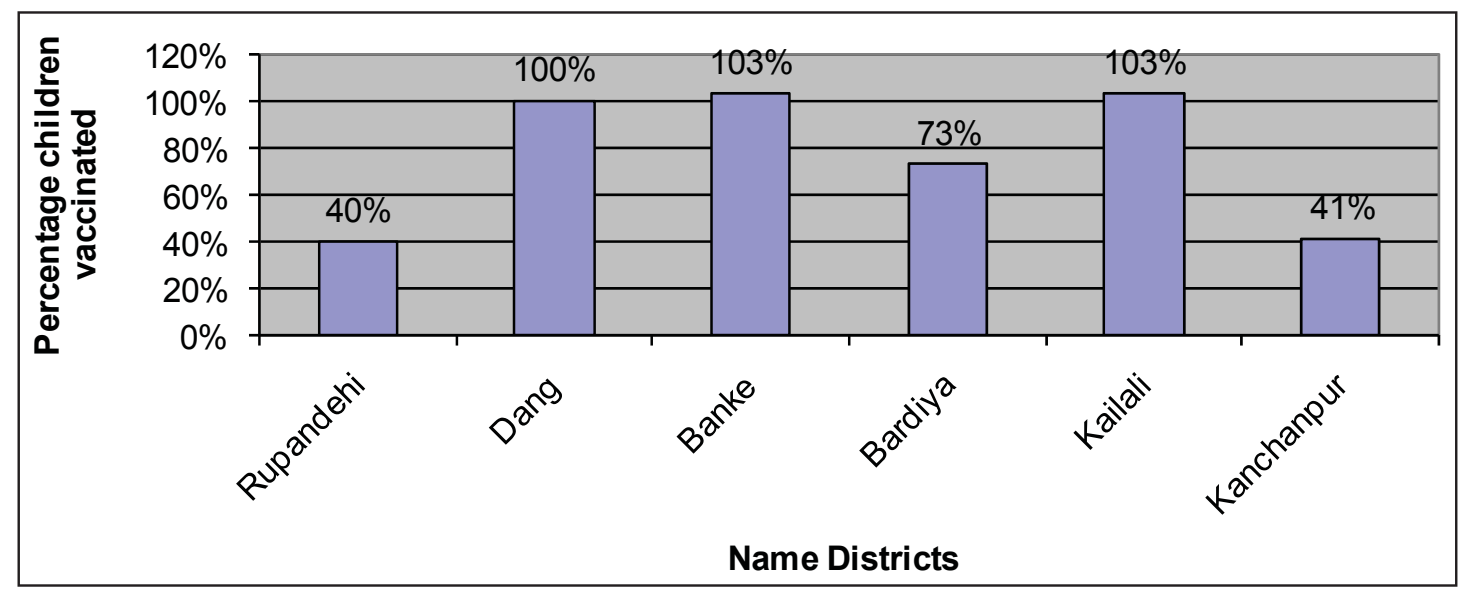

Fig 2: JE Vaccinated Children Population in Six Mid risk districts of Nepal during the Year 2006.

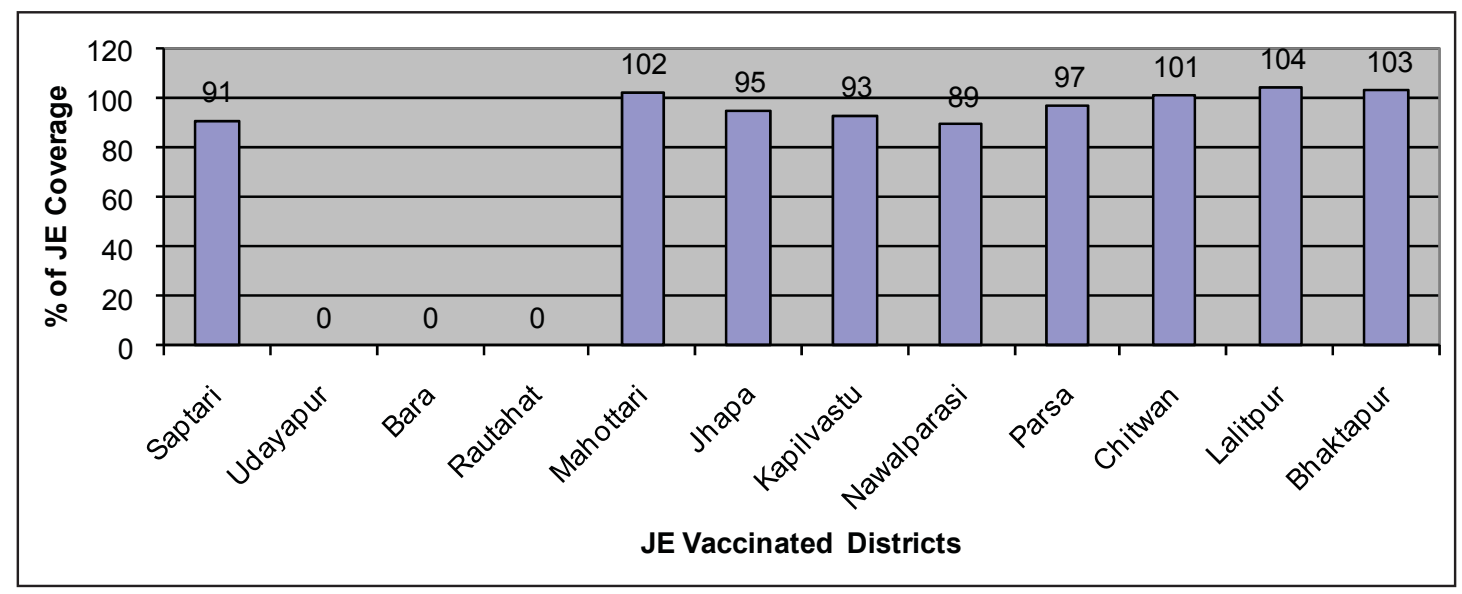

Fig 3: Percentage of JE Vaccination Coverage Children Population by districts during the Year 2008.

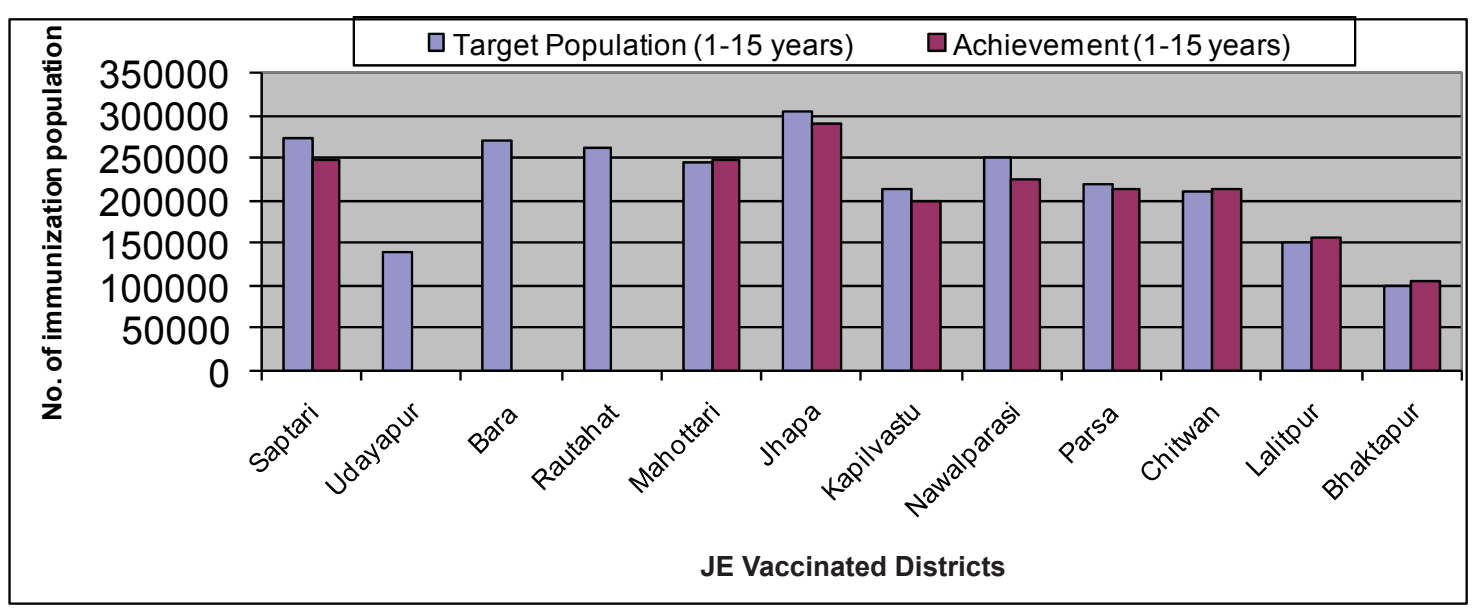

Fig 4: Comparison in number of JE Vaccinated Children Population with Targeted Population by district (2008). 
The highest coverage in percentage of JE vaccination children population are $104 \%$ in Lalitpur, $103 \%$ in Bhaktapur, $102 \%$ in Mahottari and $101 \%$ in Chitwan, out of 9 districts with the targeted children population.

Number JE vaccination children targeted population versus with JE vaccinated achievement population is presented in Fig 4.

\section{What needs to be done?}

The earlier reports have shown that the case fatality rate (CFR) is high in Nepal, and nationwide it has ranged from $15 \%$ to $46 \%$ for the years 1978 to $1994^{6}$. It has been proved that JE virus causes encephalitis in humans and abortion in pigs while no symptoms in other animals and birds. Mostly children aged five to fifteen is victimized than adults. About fifty percent of the JE survivors are left with neurological syndrome and damage to the organs ${ }^{1,4,5}$.

The people in the districts are dying due to Japanese encephalitis, and it threatens to assume epidemic proportions. The government has just started its second round of vaccination under mass vaccination program for the disease, which should have been completed by 2006. Because of the delay in vaccination, the number of patients suffering from Japanese Encephalitis may increase and take an epidemic form.

The vaccine "anti JESA-14-14-2 live attenuated" is produced in China and that it was found to be above 98 percent effective in Chinese children ${ }^{7}$. In Nepal, some two million people live in the Tarai regions considered to be highly affected areas. In order to prevent the epidemic, more than three million doses of vaccines had been arranged during the year 2005 .

Vaccination campaign against Japanese encephalitis has been started in Banke district from 26 July 2006. It is said that all 422,000 people above one year of age from Banke district were vaccinated in the campaign, which would continue until August 18, 2006. The full doze vaccine has been provided by the district public Health office. According to the schedule, the campaign would remain until July 17, 2006 in Nepalgunj municipality and from July 27 to August 18, 2006 in 46 VDCs of the districts $^{8}$.

The reduction in case incidence of Japanese encephalitis, in some countries like China, Japan and Korea has been achieved by applying certain measures such as; (Reference please)

I. Mass vaccination of suceptable group of population,

II. Vaccination of piglets of endemic areas,
III. Anti-mosquito campaign, i.e. vector control measure both larva and adult.

Thirty-five lakh of JE vaccine doses was procured by the Ministry of Health during the year 2006/2007. The vaccine is made in China by Chengdu Institute of Biological Product. This vaccine will be used in children under 15 years of age of 24 districts of JE risk and high-risk areas of Nepal.

In Nepal twenty-four districts of terai are declared as JE prone disease area. About 12.5 million people in Nepal are in JE risk category. Children who are less than 15 years of age are more prone to suffer in case of a JE outbreak. In China, JE vaccination in childrens has shown $98.4 \%$ immunity which is very encouraging 9 . During the year 2007 about 35,00,000 doses of JE vaccine is going to be procured. So far about 5000 people died due to JE from the year 1978 to 2006. Every year 3000 to 4000 people yet risk and about 200300 people die due to JE.

\section{What has to be done?}

For the reduction of JE cases in Nepal mass vaccination programme should be carried out every year for children in high risk districts of JE. Except symptomatic treatment there is no specific treatment for Japanese encephalitis. There are Japanese encephalitis vaccine prepared in Japan, China and USSR. There are two types of vaccines one liquid and other freeze dried. Vaccination can be done subcutaneously with two doses of $1 \mathrm{ml}$ each above 3 years of age and 0.5 $\mathrm{ml}$. for children upto 3 years of age at an interval of 714 days. Third doses should be given before one year. This will protect for 3 years in the endemic zone. One more booster dose after 3 years has been recommended which will give life long immunity to an individual ${ }^{10}$.

\section{Acknowledgement}

I would like to thank to the Director General of Department of Health Services Dr. M. B. Bista and Director Epidemiology Disease Control Division Dr. S. K. Banarjee, Dr. Shyam Raj Upreti, Mr. Thakur Basnet from Child Health Division, Immunization Unit and their staff working in JE epidemic districts for their kind cooperation and support during field work like vaccination and data recording. I must thank to all the staff of NZFHRC particularly Ms. Meena Dahal for data recording, reporting and paper writing

Funding: This study was supported by DDJ Research Foundation, Chagal, Kathmandu, Nepal.

Conflict of Interest: None. 


\section{References}

1. Joshi DD. Incidence of Japanese Encephalitis in Children during 1978, 1979 and 1980 Outbreak. Nepas J. 1983, 2, 18-25.

2. WHO/SEARO. Report Technical Information of Japanese Encephalitis and Guidelines for Treatment, New Delhi, India, 1979.

3. Pradhan S. Role of Mosquitoes in the Transmission of JE, Seminar on VE. Siddhartha Jaycees Souvenir, 23 Jestha 2038, Bhairahawa, 1981;6-8.

4. Khatri IB, Joshi DD, Pradhan TMS. Epidemiological Study of Viral Encephalitis in Nepal. J. Inst. Med., 1981; 4: 2;133-144.

5. Khatri IB, Joshi DD, Pradhan TMS, Pradhan S. Status of Viral Encephalitis (Japanese Encephalitis in Nepal). JNMA 1983; 66:21;1:97-110.
6. Joshi DD and Gaidamovichs. Serological Surveillance of Virus Encephalitis in Nepal, II Serological Survey of Pigs, Birds and other Animal Population for JE in the Epidemic Area following outbreak in 1970 and 1980. Bull. Vet. Sc. \& A.H. Nepal. Vol. 10 and11 1981; 82:8-12.

7. RSS Report published in the Rising Nepal June 19 2006.

8. Banke District Public Health Office. JE vaccination report for the year 2006.

9. Japanese Encephalitis Campaign Central Plan. Epidemiology and Disease Control Division and Child Health Division, Immunization Unit Department of Health Services 2006.

10. Joshi DD, Bista PR, Joshi H. Japanese Encephalitis A Zoonotic Pubic Health Problem in Nepal. NZFHRC. 2003;1-3. 